\title{
Testicular Cancer cN1 TNM Finding v7
}

National Cancer Institute

\section{Source}

National Cancer Institute. Testicular Cancer CN1 TNM Finding v7. NCI Thesaurus. Code C89261.

Metastasis with a lymph node mass $2 \mathrm{~cm}$ or less in greatest dimension; or multiple lymph nodes, none more than $2 \mathrm{~cm}$ in greatest dimension. (from AJCC 7th Ed.) 